Auf den Orient führen ahgesehen vom Fundort die griechischen Glossen zu Papinian; der Inhalt der Handschriften führt auf den Zusammenhang derselben mit einer Rechtsschule, denn der liber de iudiciis lag dem Rechtsunterricht des zweiten und dritten Studienjahres, Papinians responsa lagen dem des dritten Studienjahres zu Grunde. ${ }^{73}$ ) So mag es denn sein, dass die Handschriften, wie Mommsen andeutet, aus Alexandria stammen, wo bis auf Justinian eine Rechtsschule bestand. ${ }^{74}$ )

73) c. Omnem $\S 7$.

${ }^{74}$ ) c. Omnem $\$ 1$.

\title{
Der Process gegen den Schauspieler Roscius.
}

\author{
Von \\ Herrn Professor J. Baron \\ in Greifswald.
}

I.

Eine Mittheilung des Sachverhaltes ist nicht bloss deshalb nothwendig, weil vielen Lesern der Fall nicht gegenwärtig sein wird, sondern auch deshalb, weil Manches darin streitig ist.

C. Fannius Chärea war der Eigenthümer eines Sclaven Panurgus gewesen, welcher grosses schauspielerisches Talent besass; er schloss daher mit dem Schauspieler Roscius einen Societätsvertrag $a b$; er warf den Sclaven ein (das Eigenthum an demselben ward zwischen ihm und Roscius zu gleichen Theilen getheilt), Roscius übernahm die künstlerische Ausbildung. Der Sclave vermiethete sich nach vollendeter Ausbildung für 100000 Sesterzen; allein er wurde von dem Tarquinischen Bürger A. Flavius getödtet. Die beiden bisherigen Miteigenthümer stellten nunmehr gegen Flavius die actio legis Aquiliae an; ob die Klage auf 200000 Sesterzen gerichtet und ob diese Summe als Taxatio der Formula eingerückt war (wie Bethmann-Hollweg behauptet), das mag hier bei Seite bleiben, weil die Feststellung hiervon für den weiteren Process ohne 
Bedeutung ist. ${ }^{1}$ ) In dem Process bestellt Roscius den Fannius zu seinem Cognitor; während schwebenden Processes aher vergleicht sich Roscius mit Flavius, wie Cicero behauptet, hinsichtlich seiner eigenen Entschädigungsforderung, nach der Behauptung des Gegners hinsichtlich des ganzen Schadensanspruchs, er erhält als Vergütung ein ländliches Grundstück, das von Fannius, nicht aber von Roscius auf 100000 Sesterzen geschätzt wurde. Die Handschriften setzen diesen Vergleich in die Zeit von fünfzehn Jahren vor dem gegenwärtigen Pro-

1) Einige Worte über das von Huschke (Gaius S. 112, Note 16*) entwickelte Petitum der Formel cler l. Aquilia mögen gestattet sein. Nach Huschke ging die Formel nicht auf „quantan pecuniam ob eam rem $N$. $\mathrm{N}^{u m}$ A. $A^{\circ}$ dare oportet, denn das ergäbe eine condictio incerti, während die Klage nach l. 9 pr. $\$ 1$ D. de reb. cred. 12, 1 eine condictio certi gewesen sei. Vielmehr habe der Kläger eine bestimmte Geldsumme angeben müssen, die 1. Aquilia habe dem Kläger in den Worten "quanti in eo anno plurimi fuit" eine Forderung auf eine objectiv gewisse, wiewohl erst durch Schätzung zu ermitteInde Geldsumme gegeben; doch habe der Kläger sein subjectives Ermessen nicht schlechthin für den wahren ohjectiven Werthbetrag ausgeben können, und daher seiner Schätzung die Worte „quantive minoris id in eo anno plurimi fuit" hinzufügen müssen; daher sei die Klage ihrel" Grundlage nach immer eine certi condictio geblieben. Das würde freilich (so scheint mir) eine höchst sonderbare certi condictio sein; demm Gaius II. 50. 51. giebt als Condemnatio der cond. certae pecuniae ausdrücklich eine bestimmte, von keiner Seite her modificirbare Geldsumme an; die Condemnatio mit einer als Maximum fungirenden, mithin modificirbaren Geldsumme (taxatio) bezeichnet er als eine incerta; in der Huschkeschen Fassung der Aquilischen Formel ist die vom Kläger behauptete Geldsumme nichts als taxatio, Kläger stellt (nach Husclske) neben sie das quanti minoris des höchsten Geldwerths im letzten Jahr; der Geschworene muss regelmässig auf die letzte erkennen, weil sie allein der lex Aquilia entspricht, und wird auf die erstere nur dann eingehen, wenn sie hinter der letzteren zurückbleibt, weil es jedem Berechtigter freisteht, auf seinen Anspruch ganz oder theilweis zu verzichten. Auch was Huschke zur Begründung dieser Conception der Formel anführt, kann ich nicht anerkennen; denn die Behauptung, dass die 1. Aquil. dem Verletzten eine Forderung auf eine objectiv bestimmte, und nur erst durch Schätzung zu ermittelnde Geldsumme gegeben habe, passt doch auf eine Unzahl anderer Klagen, namentlich auch auf die rei vindicatio, deren Condemnatio nach dem Zeugniss des Gaius eine incerta ist; und die Berufung auf 1. $9 \mathrm{pr} . \$ 1 \mathrm{D}$. de reb. cred. 12, 1 beweist doch nicht, dass die act. legis Aquil. immer, d. h. in allen! Fällen eine cond. certi war. 
cess; Hotomann aber conjicirte die Zeit von vier Jahren (IV statt des handschriftlichen XV), und diese Conjectur wird noch neuerdings von Bethmann-Hollweg gebilligt. ${ }^{2}$ )

Ich bemerke aber, dass zum Verständniss des gegenwärtigen Processes die Feststellung der Zeit, zu welcher der Vergleich zwischen Roscius und Flavius abgeschlossen wurde, nicht wesentlich ist.

Roscius hatte hierdurch vor seinem früheren Socius etwas im voraus, das dieser ihm nicht gönnte. Drei Jahre vor dem gegenwärtigen Process forderte deshalb Fannius von Roscius die Summe von 50000 Sesterzen, als die Hälfte des Werthes des von Fannius auf 100000 Sesterzen geschätzten Ackers. Man streitet darüber, ob diese Forderung vor das ordentliche Gericht oder vor das Schiedsgericht gebracht worden ist. Die Ausdrücke Ciceros sind schwankend; während er im $\& 12$ aus-

2) Einerseits deshalb, weil der Vergleich unmöglich dem Fannius eine so lange Zeit verborgen bleiben konnte, andererseits weil der Process, welcher gegen Flavius angestellt worden war, unmöglich eine so lange Zeit unentschieden gelassen werden konnte. Welcher Werth indess diesen Erwägungen beigelegt werden mag: es sind, ganz abgesehen von der handschriftlichen Beglaubigung, noch andere Gründe für die Richtigkeit der Ansicht vorhanden, dass der Vergleich vor sehr langer Zeit geschlossen worden war. Schmidt nämlich hat darauf aufmerksam gemacht, dass Cicero den Hergang als eine res tam vetus, ein negotium iam confectum bezeichnet ( $\$ 38$ der Rede). Ich selbst berufe mich noch auf die Mittheilungen Ciceros in $\S 33$ :

accepit enim agrum temporibus is, quum iacerent pretia praediorum; qui ager neque villam habuit neque ex nlla parte fuit cultus, qui nunc multo pluris est, quam tunc fuit. Neque id est mirum. Tum enim propter reipublicae calamitates omnium possessiones erant incertae, nunc deum immortalium benignitate omnium fortunae sunt certae; tum erat ager incultus sine tecto, nunc est cultissimus cum optima villa...

So spricht kein Redner, der einen Zeitraum von vier Jahren bezeichnen will; auch hat die Sullanische Contrerevolution kaum einen solchen Zustand der Dinge zu Wege gebracht, dass der Bestand des Staates und der Vermögensverhältnisse als festgegründet bezeichnet werden konnte: wurde doch Volaterrä erst in demselben Jahre bezwungen, in welchem Sulla die Dictatur niederlegte!

Endlich nennt Cicero in $\$ 39$ den Vergleich zwischen Roscius und Flavius eine decisio vetus, und stellt sie der vor drei Jahren erfolgten Restipulation des Fannius als einer promissio recens gegenüber. 
drücklich von einem Compromiss spricht, nennt er im $\S 26$ den Richter iudex, den Process iudicium; indess ist letzteres schon deshalb nicht von Bedeutung, weil in demselben $\$ 26$ der Ausdruck arbiter abwechselt, und weil auch die classischen Juristen den Schiedsrichter zuweilen mit iudex bezeichnen. ${ }^{3}$ ) Von den Interpreten unseres Jahrhunderts sind Huschke, Schmidt und Bethmann-Hollweg der Meinung, dass der Yorprocess kein schiedsrichterliches Verfahren sondern ein gerichtliches Arbitrium pro socio gewesen ist. ${ }^{4}$ ) Ihre Grüncle sind folgende:

1. In den $\S \S 10$ sq. schildert Cicero den Gegensatz der iudicia und der (gerichtlichen) arbitria; der Charakter jener sei das directum, asperum, simplex, der Charaliter dieser das mite, moderatum, mit der Formel: quantum aequius melius sit dari; gleichzeitig bezeichnet or den gegenwärtigen Process als ein iudicium. Im $\S 12$ wendet er sich wieder zu dem Vorprocess zurück, den er als ein compromissum bezeichnet, und als dessen Formel er angiebt: quantum aequius et melius sit dari repromittive si peteres; ${ }^{5}$ ) nun erklärt man ${ }^{6}$ ) (len Ausdruck conpromissum aus cinem juristisch unrichtigen, rednerischen Gebrauch und schliesst aus der Formel, dass der Vorprocess ein gerichtliches Arbitrium gewesen sei. Aber gerate lim der Formel willen kamn ich nicht zustimmen; sie deckt sich nicht mit der früher von Cicero für die gerichtlichen arbitria angegebenen; die der letzteren lautete:

quantum aequius melius sit dari die des Vorprocesses:

3) 1. $34 \$ 1$ D. de min. 4, 4; 1. 41 D. de rec. 4, s; l. 4 D. de tul. 26,5 .

4) Rudorff (R. Rechtsg. Bd. $2 \$ 68$ N. 10) jimmt ein Compromiss an, aber er hat leider seine Ansicht nicht näher ausgeführt. Puchta in seiner Abh, über Ciceros Rede (Rhein. Mus. f. Jurispr. Bd. 1 S. 321 f.) berührt die Frage nur sehr kurz, und lässt sie unentschieden.

5) Ueber die Worte si peteres s, unten die Note 7.

6) Bethmann-Hollweg Bd. 2 S. 809 Note 12. Hingegen Schmidt in seiner Inauguraldissertation p. 4 und Huschke in Schneiders Jahrb. 7, 484 behaupten, dass auch bei bonae fidei iudicia ein Strafversprechen für den Fall des Lnterliegens eingegangen zu werden pflegte, und lediglich dies werde durch das Wort compromissum ausgesprochen; ilnen hat bereits Bethmann-Hollwey a. a. O. erwiedert, dass die Quellen nichts hiervon wissen. 
quantum aequius et melius sit dari repromittive. . . Uns ist keine gerichtliche Formel bekannt, die auf dari repromittive gerichtet wäre; neben dem dari kommt das fieri, das damnum decidere, vielleicht auch das praestare vor, niemals aber das repromittive. Und diese Formel, wenn sie existirte, müsste erhalten sein, da der Geschworeue bei allen bonae fidei iudicia die Berechtigung zur Auferlegung von Cautionen hat:

l. 38 pr. D. soc. 17, 2: pro socio arbiter prospicere debet cautionibus in futuro damno vel lucro pendente ex ea societate; quod Sabinus in omnibus bonae fidei iudiciis existimavit sive generalia sunt, veluti pro socio, negotiorum gestorum, tutelae, sive specialia veluti mandati, commodati, depositi.

Man lese doch nur die beiden Formeln, welche uns im zwanzigsten Capitel der lex Rubria überliefert sind, und welche gerade eine Klage wegen unterbliebener stipulatio damni infecti betreffen; beide Male lauten sie auf: quicquid eum Q. Licinium ex ea stipulatione L. Seio dare facere oporteret ex fide bona, trotzdem in beiden wiederholentlich hervorgehoben wird, dass der Verklagte Q. Licinius eo nomine qua de re agitur L. Seio damni infecti repromittere (satisdare) noluit. - Erklärlich wird die Formel des Vorverfahrens quantum aequius et melius sit dari repromittive ${ }^{7}$ ) erst dann, wenn wir es uns als ein schiedsrichterliches denken; einerseits nämlich wird jeder Compromiss mit einem gegenseitigen Strafversprechen eingeleitet; andererseits war die Fassung dieses Versprechens keine fest abgeschlossene; die von den Compromittenten einzugehende Stipulation konnte also dahin gerichtet sein, dass Jeder eine Strafe versprach für den Fall, dass er dem ihm vom Schiedsrichter auferlegten dare oder repromittere nicht nachkam. Die Formel quantum aequius et melius sit dari repromittive ist nichts als ein Theil der von Fannius und Roscius behufs Einleitung des schiedsrichterlichen Verfahrens eingegangenen Strafstipulation; die Compromittenten verweisen

7) Nach repromittive haben die Editionen „si pareret“, so dass man wieder an eine Processformel erinnert wird, allein die Handschriften lesen „si peteres“ oder „si peieres;“ mag auch dieser Text corrupt sein: jedenfalls fällt der Hinweis auf die Processformel hinweg. 
den Schiedsrichter auf die Billigkeit, und unterwerfen sich, falls sie seinen nach der Billigkeit gefällten Spruch nicht befolgen, einer Strafe. Bestätigt wird meine Meinung durch das Wörtchen ve in repromittive; ich möchte es als unerhört bezeichnen, dass einem Geschworenen als Inhalt der Verpflichtung des Verklagten wahlweise die Leistung und das Versprechen einer Leistung angegreben wird; wo eine Caution geschuldet, aber nicht geleistet wird, da wird auf den Geldwerth condemnirt:

1. 19 D. de ev. 21, 2: si dupla non promittcretur et co nomine agetur, dupli condemmandus est reus. ${ }^{8}$ )

Der Schiedsrichter hingegen, welcher ein völlig freies E1messen hat, welcher bei seinem Spruch nicht an die gesetzlichen Vorschriften gebunden ist, ${ }^{9}$ ) wird oft aus Billigkeitsrücksichten statt des sofortigen dare ein Versprechen auferlegen. - Endlich stimmt auch der Fortgang der Darstellung in $\$ 3$ 12. 13, in welchen Cicero auf die Person und die Stellung des Urtheiler's eingeht, zu meiner Auffassung. Im $\S 12$ berührt Cicero die Person des Urtheilers im Vorprocess resp. im gegenwärtigen Process; in beiden ist es C. Piso; nun fügt Cicero hinzu:

eundem tu arbitrum et iudicem sumebas? e idem et infinitam largitionem remittebas et eundem in angustissimam formulam sponsionis concludebas?

Die infinita largitio passt nicht auf den gerichtlichen arbiter, er ist nicht von allen gesetzlichen Vorschriften befreit, und sein Urtheil kann angefochten werden (zu Ciceros Zeit nur in sehr beschränktem Umfange). Dahingegen passt die infinita largitio durchaus auf den Schiedsrichter, dessen Spruch, or mag billig oder unbillig sein, unanfechtbar ist:

1. $27 \S 2$ D. de rec. 4,8 : stari autem debet sententiae arbitri, quam de re dixerit, si ve a equa sive iniqua sit . . ${ }^{10}$ )

8) cf. $1.11 \S 9$ D. de act. emti 19, 1: idem ait, non tradentem, quanti intersit, condennari; satis autem non danten, quanti plurimum auctorem periclitari oportet.

9) $1.27 \S 2$ D. de rec. 4,8 .

10) Vgl. auch die Schilderung bei Seneca de henef. 3, 7 : libera et nullis adstricta vinculis religio sowie de clem. 2, 7: liberum arbitrium 
Im $\S 13$ berüht Cicero dic Stellung des Urtheilers im Vorprocess resp. im gegenwärtigen:

caeteri quum ad indicem causam labefactari amimadvertunt, ad arbitrum conveniunt, hic ab arbitro ad iudicem venire est ausus...

Cicero beginnt also mit der Bemerkung, dass der Kläger bei zweifelhaften Rechtsansprüchen sich nicht an einen iudex wende, sondern an einen arbiter; die Bemerkung ist nur dann haltbar, wenn man unter arbiter einen Schiedsrichter versteht; denn Cicero spricht sie in ganz allgemeiner Weise aus, er unterscheidet nicht die verschiedenen Arten der Obligationen, und wie wäre es denkbar, dass ein Darlehnsgläubiger, statt des iudex einen arbiter im Sinne eines gerichtlichen arbiter wälltt?

2. Als zweiten Grund für die Meinung, dass der Vorprocess ein ordentliches gerichtliches Verfahren gewesen; wird angeführt, dass der Kläger den Arbiter gewählt habe, während über den Schiedsrichter beide Theile von vornherein übereinkommen. ${ }^{11}$ ) Dieser Behauptung liegt irgend ein Míssverstiindniss zum Grunde; Cicero spricht von der Bestellung des Urtheilers im Vorprocess an zwei Stellen:

$\S 12 \ldots$ Ipse C. Piso est; eundemne tu arbitrum et iudicem sumebas?

$\S 26 \ldots$ Dic nunc, Roscium abs te petisse, ut familiarem suum sumeres arbitrum ...

In keiner von beiden erklärt Cicero, dass Fannius im Vorprocess den Piso als Richter vorgeschlagen habe (- das ist doch der Sinn der gegnerischen Behauptung -); der Vorschlag wird bekanntlich mit iudicem ferr e ausgedrückt ; Cicero aber braucht beide Male die Redeweise: iudicem, arbitrum sumere; dieser Ausdruck wird aber gerade gebraucht, um die Einigkeit beider Theile zu bezeichnen, und Rudorff ${ }^{12}$ ) hebt ausdrücklich hervor, dass er besonders beim Compromiss üblich ist; man vergleiche

habet, non sub formula sed ex aequo et bono julicat et absolvere illi licet, et quanti vult taxare litem.

11) Bethmann-Hollweg a. a. O. Note 13.

12) Röm. Rechtsg. Bd. 2 9 N. 3. 
1. 33 D. de rec. 4,8 : arbiter ita sumitus ex compromisso ... Pauli sent. rec. $\mathrm{V}, 5^{\mathrm{a}} \S 1: \ldots$ ex compromisso autem iudex sumtus rem iudicatam non facit....

Hiernach lässt sich mit viel melır Recht behaupten, dass Cicero's Bericht über die Wahl des Urtheilers den Vorprocess zu einem schielsrichterlichen Verfahren stempelt.

3. Als drittes Argunent fungirt der Ausgang des Vorprocesses; Cicero schildert ihn im $\S 26$ in folgender Weise: .. Dic pactionem fecisse (Roscium), ut absolveretur; non pepigit. Quaere, quare sit absolutus; quod erat summa innocentia et integritate. Quid enim factum cst? Venisti domum ultro Rocii; satis fecisti; quod temere commisisti ${ }^{13}$ ) in iudicium ut denuntiaret, rogasti ut ignosceret; te alfuturum negasti; debere tibi ea societate nihil clamitasti; iudici hic denuntiavit; absolutus est. Tamen fraudis ac furti mentionem facere audes? Perstat in impudentia; pactionem enim, inquit, mecum fecerat, idcirco videlicet ne condemnaretur.

Hiernach ist Roscius freigesprochen worden, und zwar, weil Fannius (nachıdem Piso einen für Fannius höchst günstigen Vergleich vorgeschlagen hatte), den Roscius beauftragte, vor dem Richter zu erklären, dass er die Klage ohne Grund angestellt habe, und weil er zur Behräftigung dieses Auftrags vor dem Richter nicht erschien. Bethmann-Hollweg weist nun darauf hin, dass das Compromiss durch Vergleich aufgehoben werle, ohne dass ein Urtheil erfolge, ${ }^{14}$ ) und behauptet, dass die Freisprechung des Roscius erfolgte, trotzdem er sich mit Fannius verglichen; er schliesst daraus, dass das Verfahren kein compromissarisches gewesen sein könne. Diese Argumentation leidet an (lem Fehler, dass sie einen unter den Parteien lebhaft ventilirten Streitpunkt ohne weiteren Beweis im Simne der eimen entscheidet. ${ }^{15}$ ) Der oben angeführte Text der Ciceronianischen Rede zeigt ja, dass Roscius den Vergleich leugnete, Fannius ihn behauptete, und ich werde später nach-

13) Schon Bethmann-Hollweg hat die Conjectur „compromisisti“ aufgestellt.

14) I. 32 §§ 3.5 D. de rec. 4,8 .

15) Dieser Vorwurf trifft nur Bethmann-Hollweg, nicht Selımidt; dieser letztere (S. 5 Note 12) macht auf den Streitpunkt aafmerksam. 
weisen, dass der Vergleich von Piso vorgeschlagen, aber bloss von Fannius und nicht von Roscius vollzogen worden ist.

Die Freisprechung des Roscius erfolgte, weil Fannius durch diesen dem Arbiter erklären liess, dass er keinen Grund zur Aufrechterhaltung des Compromisses habe, m. a. W. dass er es fallen lasse. Dass übrigens die Freisprechung in Abwesenheit des Klägers erfolgte, ist kein Grund gegen die Annahme eines Compromisses; denn wenn auch in der Regel der Schiedsrichter nur in Anwesenheit beider Parteien sein Laudum fällen soll, so können doch die letzteren verabreden, dass die Abwesenheit kein Hinderniss sein solle, ${ }^{16}$ ) und die Cautelarjurisprudenz der Römer hat sicherlich hierauf die gebülırende Rücksicht genommen. ${ }^{17}$ )

Im Vorhergehenden ist die gegnerische Meinung nicht bloss widerlegt sondern auch die meinige begründet worden. Noch aber ist ein Hauptargument anzuführen.

Bethmann-Hollweg ${ }^{18}$ ) allein hat die volle Consequenz der gegnerischen Meinung gezogen. Da nämlich Cicero wiederholt hervorhebt, dass der Vor - und der gegenwärtige Process denselben Gegenstand betreffen, so würde, falls die gegnerische Meinung richtig wäre, der Satz aufgestellt werden müssen, dass die condictio (der gegenwärtige Process) durch die Litiscontestatio mit der actio pro socio (dem angeblichen Charakter des Vorprocesses) nicht consumirt wurde. Das wird von Bethmann-Hollweg behauptet, aber es widerspricht direct der

1. 5 D. de exc. rei iud. 44, 2: de eadem re agere videtur, et qui non eadem actione agat, qua ab initio agebat, sed etiamsi alia experiatur, de eadem tamen re. Utputa si quis mandati acturus, quam ei adversarius judicio sistendi causa promisisset, propter eandem rem agat negotiorum gestorum vel condicat, de eadem re agit.

Es lässt sich überdies aus inneren Gründen nicht halten. Ich werde später die condictio certi mit der vindicatio non expressa causa vergleichen, - ein Vergleich, der um deshalb. zulässig ist, weil unzweifelhaft die gegen Roscius angestellte

16) $1.27 \$ 4$ D. de rec. 4,8 .

17) Dass dies auch die Meinung Rudorffs war, folgt aus seinem Entwurf des Compromissvertrages (R. Rechtsg. Bd. $2 \S 68$ S. 224f.).

18) a. a. O. Note 42 auf S. 820 . 
Condictio in ihrer Formel keine causa debendi enthielt;19) nun lehren die Quellen, dass, wenn Jemand die vindicatio expressa causa angestellt hat, er später die vindicatio nicht mehr non expressa causa sondern nur alia causa expressa anstellen dürfe :

$111 \S 2$ D. de exc. rei iud. 44, 2: si quis autem putat fundum suum esse eo, quod Titius eum sibi tradiderit, si postea alia ex causa petat, causa adiecta non debet summoyeri exceptione.

Es ist eine zwingende Analogie vorhanden, dass derjenige Gegenstand, welcher mit der act. pro socio eingeklagt worden, nicht später mit der der Causa entbehrenden Condictio gefordert werden kann; denn in der letzteren würde ja die im Vorprocess geltend gemachte Causa wieder mitbegriffen und die exc. rei in indicium deductae resp. iudicatae begründet sein. - Uebrigens macht Cicero in $\S 25$ dem Kläger einen Vorwurf, weil er gegenwärtig nicht die act. pro socio sondern die cond. certi angestellt habe:

nam quo tu tempore illa formula (scil. pro socio) uti noluisti, nihil hunc in societatem fraudis fecisse iudicasti ...

Der Vorwurf wäre undenkbar, wenn Fannius schon vorher einmal die act. pro socio angestellt hätte, da ihm damn die exc. rei in iudicium deductae entgegengestanden haben würde; über dieses Argument kommt Bethmann-Hollweg (S.822f.) nur daclurch hinweg, dass er den Cicero der "absichtlichen Ignorirung" beschuldigt; es ist dies ein wohlwollender Ausdruck für Lüge, und eine Lüge, die dem Richter sofort offenbar ist, darf man doch nur einem kopflosen Advocaten zutrauen.

Ich wende mich $z \mathfrak{u}$ dem von Piso vorgeschlagenen Vergleich, zufolge welches das Vorverfahren ein Ende nahm, über dessen Abschluss aber, wie bemerkt, die Parteien streiten. Cicero schildert ihn mit folgenden Worten:

Tu enim (Piso) Q. Roscium pro opera, pro labore, quod cognitor fuisset, quod vadimonia obisset, rogasti ut Fannio daret HS cccim hac condicione, ut, si quid ille exegisset a Flavio, partem eius dimidiam Roscio dissolveret (\$ 38).

19) Man ist hierüber auf allen Seiten einig, jch komme darauf später zurück; vgl. vorläufig das 4. und 5. Cajjitel der Rede. 
Man erinnere sich, dass im Vorverfahren Fannius bloss 50000 Sesterzen gefordert hatte, indem er den Werth des von Flavius an Roscius gegebenen Grundstücks auf 100000 Sesterzen schätzte. Was vermochte den Piso, über das Petitum des Klägers bei seinem Vergleichsvorschlage hinauszugehn? Frühere Interpreten haben deshalb die Vergleichssumme durch Conjectur herabzusetzen gesucht; Schmidt und Bethmann-Hollweg halten an der handschriftlichen Summe fest, weil nach dem Bericht Ciceros ${ }^{20}$ ) einerseits Fannius die Summe von 100000 Sesterzen als Schuld des Roscius in seine Adversarien eintrug, andererseits, weil Roscius dem Fannius 50000 Sesterzen als Hälfte der Schuld zahlte ( $\$ 51$ der Rede). Ohne Zweifel muss man ihnen zustimmen. Cicero giebt ja auch zwei Gründe für die Ueberschreitung des Petitum an: die Mühewaltung des Fannius als Cognitor des Roscius, die Gefahren, die ihm aus den Vadimonien erwuchsen. Vielleicht sind diese Gründe nur eine wohlwollende Verhüllung derjenigen Motive, welche den Piso in Wirklichkeit leiteten. ${ }^{21}$ )

Man kann sich nämlich bei Beurtheilung des Vorprocesses auf einen doppelten Standpunkt stellen: auf den juristischen oder auf den des guten Anstandes.

Vom juristischen Standpunkt aus kann man die Frage aufwerfen, ob zur Zeit überhaupt eine Societas zwischen Roscius und Fannius bestand; die Societas bezüglich des Panurgus war aufgelöst durch dessen Tödtung; ${ }^{22}$ ) die act. legis Aquiliae stand jedem Miteigenthümer bezüglich seines Antheils völlig unabhängig und ohne Zusammenhang mit der des anderen $\mathrm{zu}$; dahingegen kann die Behauptung aufgestellt werden, dass die früheren Socii eine neue Societas bezüglich des Processes gegen Flavius eingegangen waren ( - ich komme hierauf später unter IV. zurück -); von hier aus kann man höchstens den

20) Vgl. \$§ 4. 51 der Rede.

21) Bethrnann-Hollweg erklärt den Vergleichsvorschlag für parteiisch zu Gunsten des Fannius, ohne die Parteinahme zu motiviren. Schmidt denkt, dass noch andere Societätsforderungen bestanden, aber mit keinem Worte werden solche erwähnt; Huschke spricht von Vorspiegelungen des Fannius gegenüber Roscius, um diesen zu der hohen Summe zu hewegen; hätte Cicero ihm diese nicht vorgehalten?

${ }^{22)}$ Daher Ciceros Worte in $\S 38$ : in societate dissoluta. 
Roscius für schuldig erachten, die Hälfte des empfangenen Vergleichsobjects an Fannius herauszugeben; die darüber hinausgehende Vergleichsproposition des Piso ist juristisch unhaltbar.

Anstandsrücksichten freilich mussten den Roscius unbedingt abhalten, hinter dem Rücken des Fannius sich mit Flavius zu vergleichen; ein Vergleich hinter dem Rücken des Fannius ist es gewesen, sonst wäre er Fannius nicht so viele Jahre unbekannt geblieben. Fannius schrie über Betrug und Diebstahl, und noch im gegenwärtigen Process wiederholte er dies (§ 16-26 der Rede). Natürlich ist diese Anklage nicht wörtlich und juristisch zu nehmen, sondern als der Vorwurf eines rücksichtslosen, im Handel und Wandel unerlörten Benehmens. Man denke nur: eine materielle Auslage hatte nur Fannius gehabt, er allein warf den Panurgus in die Societät, der Beitrag des Roscius war ein Zeitaufwand, und sicherlich ein Zeitaufwand, der den Roscius in seinem schauspielerischen Gewerbe nicht störte, ${ }^{23}$ ) also ihm nichts kostete; hierauf fiihrte Fannius auch den Process gegen Flavius nicht bloss fiur sich sondern auch für Roscius, er also benahm sich in der Art eines braven Gesellschafters, und trennte sein Interesse nicht von dem des Roscius. Und nummehr vergleicht sich Roscius für seinen Theil mit Flavius! Das formelle Recht hierzu besass er unzweifelhaft; gebot aber nicht die gute Sitte, dass er alle Vergleichspropositionen des Flavius, wenn sie nur seinen 'Theil betrafen, zurückwies? Musste er nicht wenigstens vor $\Lambda$ bschliessung des Vergleichs dem Fannius Mittheilung machen, und diesem Gelegenheit zur Wahrung seines Interesses geben? Ich weiss nur Einen Entschuldigungsgrund für Roscius: es ist die bekannte schauspielerische Leichtsinnigkeit oder (wenn dies Wort einem Roscius gegenüber zu hart ist) Unerfahrenheit in allen Geldsachen. Cicero hat gut reden, dass Fannius sich auch hätte vorsehen und auch einen Vergleich hätte abschliessen sollen ( $\$ 32$ der Rede); der Umstand, dass Flavius nicht baares Geld, sondern einen Acker leistete, beweist doch augenscheinlich, dass er nicht vollkommen zahlungsfähig war, und dass

${ }^{23}$ ) Cicero sagt bloss, dass es dem Roscius viel Mühe und Aerger kostete: summo cum labore, stomacho miseriaque erudiit ( $\$ 31$ der Rede). 
Roscius auf Kosten seines früheren Socius sein eignes Interesse wahrnahin. In der That, der Charakter des Roscius lief Gefahr, mit einem Makel behaftet zu werden; für eine der Oeffentlichkeit angehörige und wegen ihrer künstlerischen Grösse in den höchsten Gesellschaftskreisen zugelassene Persönlichlkeit war die Gefahr von grosser Bedeutung; die gesellschaftliche Stellung des Roscius stand auf dem Spiel. Hier ist das grosse Geschick des Piso anzuerkennen. Die bisherigen Interpreten ${ }^{24}$ ) erklären ihn für parteiisch, und machen ihm eine entschiedene Begünstigung des Fannius zum Vorwurf. Ganz das Gegentheil findet statt; er räth dem Roscius, sich energisch aus der schmutzigen Affaire zu ziehen, und - wenn der Ausdruck gestattet ist - den ganzen Bettel dem Fannius an den Hals zu werfen; bloss die Ehre des Roscius liegt ihm am Herzen, diese aber wahrt er materiell und formell; materiell : durch die (offenbar fadenscheinige) Bezugnahme auf die Mühewaltung und Gefahren des Fannius als Cognitor, ${ }^{25}$ ) formell: durch die ungemein höfliche Form des Vergleichsvorschlags, tu enim (sagt Cicero in $\S 38$ ) Q. Roscium ... rogasti ut Fannio daret HS cccrops; nicht einen puren schiedsrichterlichen Vergleichsvorschlag macht Piso dem Roscius, er unterstützt inn durch seine Bitte, und um zugleich der Welt darzuthun, dass Roscius keineswegs ohne Rechtsansprüche sei, so verpflichtet er den Fannius zu dem Versprechen, die Hälfte dessen, was er später von Flavius erhalten sollte, an Roscius herauszugeben. Natürlich war durch diesen Vorschlag Fannius so erfreut, dass er seinen Gleichmuth verlor; er eilt zu Roscius, und dort kommt es $\mathrm{zu}$ der bereits oben erwähnten Scene: Fannius bekennt laut, völlig im Unrechten zu sein, er habe gar nichts aus der Societät zu fordern, er habe ganz ohne Grund das Compromiss geschlossen, er werde auch nicht mehr vor dem Arbiter erscheinen, er bat um Verzeihung, er erschien

24) Zuletzt noch Bethmann-Hollweg, S. 808 in Note 11 .

25) Es ist hierbei hervorzuheben, dass nach Ciceros Mittheilung die ganzen 100000 Sesterzen für diese Mühewaltung und Gefahren gezahlt werden, und dass es falsch wäre, die Summe in zwei Hälften getheilt zu denken: die eine Hälfte für die Cognitorfunction, die andere Hälfte als Zahlung der Societätsschuld. Dies thut Bethmann-Hollweg. 
nicht mehr vor dem Arbiter, und Roscius wurde von dem letzteren freigesprochen ( $\$ 26$ der Rede).

Ist der Vergleich erfüllt worden?

Unzweifelhaft von Fannius; Cicero erzählt nicht bloss, dass er das Versprechen abgegeben, ${ }^{26}$ ) sondern er fülırt den Wortlaut der Restipulation an:

Qgod a Flavio abstulero, Partem dimidiam inde Roscio me Soluturum spondeo ( $\$ 37$ der Rede).

Was Roscius betrifft, so wird die Frage, ob er die Zahlung der 100000 Sesterzen in einer juristisch bindenden Form versprochen, erst später erörtert werden, da sie eben eine Hauptfrage des gegenwürtigen Processes ist. Jetzt mache ich darauf aufmerksam, dass Piso an sofortige Zahlung dachte (rogasti ut daret im $\S 38$ ); Roscius zahlte denn auch die eine Hälfte mit 50000 Sesterzen ( $\$ 51$ der Rede); die andere Hälfte liess er unbezahlt, vielleicht deshalb, weil er hoffte, dass Flavius an Fannius eine Zahlung machen werde; in der That behauptet Roscius im gegenwärtigen Process, dass Flavius dem Fannius 100000 Sesterzen gezahlt habe; Fannius freilich bestreitet diese Behauptung, und der Beweis, welchen Cicero antritt, ( $\$ 42-51$ der Rede), kann keineswegs als ein gelungener gelten. Er beruft sich auf den Richter in dem zwischen Fannius und Flavius schwebenden Vorprocess; dieser, der Römische Ritter Cluvius, habe zweien Senatoren, dem T. Manilius und C. Luscius im Privatgespräch die betreffende Mittheilung gemacht; die Senatoren beeideten ihre Aussage und Cicero liess sie verlesen. Ich verstehe nicht, wie BethmannHollweg auf Grund dieser Aussage es als feststehend annimmt, dass Flavius an Fannius die Zahlung von 100000 Sesterzen wirklich geleistet haben; die Zeugen sind doch reine testes de auditu, und der es ihnen nittheilte, war unbeeidet. Ich begreife nur soviel, dass Roscius von der Zahlung im höchsten Grade überzeugt war, und dass er deshalb sich weigerte, die zweite Hälfte der von Piso vorgeschlagenen Summe

26) Satisfecisti in $\$ 26$ der Rede; ferner: quil malum stultitia fuit Roscius, qui ex iurisperitorum consilio et auctoritate restipularetur a Fannio diligenter, ut, quod is exegisset a Flavio, dimidiam partem sibi dissolveret im $\$ 56$ der Rede. 
zu zahlen. Zur Compensation stellte er seine Gegenforderung aus der Restipulation, die doch durch die angebliche Zahlung des Flavius an Fannius existent geworden war, nicht; er konnte dies nicht, weil dies $\mathrm{zu}$ damaliger Zeit noch nicht zulässig war (Gaius 4, 63 sqq.), sondern er leugnete, dass er zur Zahlung verpflichtet sei.

\section{II.}

Man erwartet nach dem Vorhergehenden, dass Fannius gegen Roscius die Klage auf Erfüllung des Vergleichs, soweit letzterer noch unerfüllt war, anstellte. Als solche Klage pflegt man, falls nicht der Vergleich in einen bestimmten benannten Vertrag ausläuft, die actio praescriptis verbis anzugeben, da sich der Vergleich als ein Innominatcontract darstellt. Iṃ vorliegenden Falle kann von der act. praescr. verbis nicht die Rede sein; ich lasse dabei die Streitfrage, ob sie schon zur Ciceronianischen Zeit existirte, bei Seite, ${ }^{27}$ ) und hebe nur hervor, dass es sich hier um die Form facio ut des handelt (Fannius hat promittirt, Roscius soll zahlen), und dass bei dieser Form bekanntlich noch Paulus die act. praescr. verbis versagt. ${ }^{28}$ )

Die angestellte Klage ist die condictio certae pecuniae; ${ }^{29}$ ) Cicero bezeichnet die Klage überhaupt nicht mit dem technischen Namen, er beschreibt sie nur mehrmals:

$\S 10$ pecunia tibi debebatur certa, quae nunc petitur per iudicem...

$\S 13$ praeterea enim, quemadmodum certam pecuniam petere possit, non reperio.

$\S 14$ pecunia petita est certa ...

man darf sich deshalb nicht wundern, dass er den Ausdruck condictio certae pecuniac nicht gebraucht; er giebt ihre Formel an:

$\S 11$ si paret HS mpo dari... sie ist dieselbe wie die bei Gaius III, 91 und im $\$ 1$ der In-

27) Vgl. Rudorffs R. Rechtsg. Bd. $2 \S 49$ N. 19, Pernice, Labeo Bd. 1 S. $481 \mathrm{ff}$.

28) 1. $5 \$ 3$ D. de pr. verb. 19,5 .

${ }^{29}$ S. hierzu die Heimbachsche Doctordissertation: obs. iur. Rom. liber. $\$ 1$. Lips. 1834 . 
stitutionen qu. mod. re contr. 3, 14 uns erhaltene Darlehusformel, welche unstreitig eine cond. certae pecuniae war:

is quoque qui non debitum accepit ab eo, qui per errorem solvit, re obligatur, nam perinde ei condici potest ,si paret eum dare oportere ${ }^{6}$, ac si mutuum accepisset.

Auch stimmt sie mit der bei Gaius 4, 64 erhaltenen Formel des Argentarius, die unzweifelhaft eine condictio certae pecuniae war:

argentarius cogitur cum compensatione agere, et ea compensatio verbis formulae exprimitur, adeo quidem, ut ab initio compensatione facta minus intendat, sibi dari oportere, ecce enim si sestertium $X$ milia debeat Titio, atque ei $X X$ debeantur, sic intendit: „si paret Titium sibi X milia dare oportere amplius quam ipse Titio debet"...

Hiernach steht unter den Interpreten der Charakter der Klage als condictio certae pecuniae fest.

Auch das steht unter den Schriftstellern fest, dass in der Klagformel die causa des klägerischen Anspruchs nicht angegeben war; denn nicht bloss fehlt die Causa in dem oben wörtlich mitgetheilten Bruchstück der Formel (gleichwie in den übrigen aus Gaius und den Institutionen citirten Bruchstücken), sondern auch die Deduction Ciceros in den $\$ \$ 13.14$ zwingt uns zu dicser Meinung:

iam duae partes causac sunt confectae: adnumerasse sese negat, expensum tulisse non dicit, quum tabulas non recitat; reliquum est, ut stipulatum se esse dicat; praeterea enim, quemadmodum certam pecuniam petere possit, non reperio . . .

Die Klage des Fannius, meint Cicero, kann eine von drei Causae haben, und deshalb geht er alle drei durch; dass nicht alle drei in der Formel gestanden haben können, bedarf keiner Ausführung; mit Nothwendigkeit ergiebt sich, dass keine in der Formel stand. ${ }^{30}$ )

Enthielt aber die Formel keine Causa ( - ich habe dafür in meinen Pandecten $\S 84$ den Namen ,abstracte Formel" vorgeschlagen -), so folgt mit Nothwendigkeit, dass sie auf irgend welche Causa gestützt werden konnte. Die Ansicht, die ich hier ausspreche, ist nicht neu; ich stiitze sic

30) Savigny, System Bd. 5 S. 610. 
nur auf ein neues Argument. Es bandelt sich um die bekannte Streitfrage, ob, wie l. 9 D. de reb. cred. 12,1 besagt, die cond. certi auf jede Forderung anwendbar ist, welche der Gläubiger als certum qualificirt. Die bejahende Ansicht führte bei den Byzantinern ${ }^{31}$ ) zur Aufstellung der condictio certi generalis, Keller ${ }^{32}$ ) bekennt sich zu ihr, indem er die cond. certi mit jeder anderen actio ex contractu oder ex delicto electiv concurriren lässt; und ihm sind Krüger ${ }^{33}$ ) und Ubbelohde ${ }^{34}$ ) gefolgt. Die herrschende Ansicht ist bekanntlich die entgegengesetzte; von Savigny an bis zu Bethmann-Hollweg ${ }^{35}$ ) und Bekker ${ }^{36}$ ) erklärt man die Condictio an feste bestimmte Entstehungsgründe gebunden.

Auch ich bekenne mich, wie Keller, zur bejahenden Ansicht. Gerade die Rede Ciceros für Roscius giebt mir das schon oben berührte neue Argument in die Hand: nicht auf die äusserliche Autorität der 1. $9 \mathrm{D}$. de reb. cred. 12, 1 stütze ich mich (das ist die Hauptschwäche in der bisherigen Vertheidigung), sondern darauf, dass die cond. certi keine Causa enthält; an diesem Orte lasse ich die sonstigen Zeugnisse bei Seite und beschränke mich auf Ciceros Rede.

Eine abstracte persönliche Klage bietet offenbar das Seitenstück zu der actio in rem non expressa causa. Von der letzteren sagt l. $14 \S 2 \mathrm{D}$. de exc. rei iud. 44, 2 ausdrücklich, dass der Kläger sich auf irgendwelche Causa stützen könne:

... at quum in rem ago non expressa causa, ex qua rem meam esse dico, omnes causae una petitione apprehenduntur...

31) Basilicorum lib. 23 t. 1. scholion Stephani (Heimbachsche Ausgabe 2, 591).

32) Röm. Givijpr. $\$ 88$ Note 1107 der 5. Ausg. Schon vor Keller hat Sclimidt in seinem Commentar S. 6 zu unserer Rede die gleiche Ansicht aufgestellt; ebenso Hasse im Rhein. Mus. Bd. 6 S. 75 sq.

$\left.{ }^{33}\right)$ Proc. Cons. S. 105-110.

34) Ipso iure compensatur S. 186 N. 11 S. 192 N. 21.

3s) Civilprocess Bd. $2 \S 93$ Anm. 78.

36) Actioljen 1, $137 \mathrm{ff}$. 
Warum sollte denn die abstracte persönliche Klage anderen Grundsätzen unterworfen sein? Ist die Formel die Basis für die Verhandlung der Parteien vor dem Geschworenen und für das Urtheil des Geschworenen, so ist bei abstracter Klagformel der Kläger in voller Freiheit, irgend eine Causa anzuführen. Wir werden später sehen, dass Fannius sich in Wahrheit auf verschiedene Causae stützte.

Vorläufig muss noch ein Finwand, der denkbar ist, zurïckgewiesen werlen. Wenn nämlich die cond. certi eine abstracte Klage ist, und demgemäss der Kläger sich auf irgendwelche Causa stützen kann: mit welchem Recht behauptet denn Cicero, dass Fannius sich höchstens auf Darlehn, Stipulation, Expensilation stuitzen dürfe, eine sonstige Causa der Klage sei ihm unerfindlich?

$\S 13$. Jam duae partes causae sunt confectae; adnumerasse sese negat; expensum tulisse non dicit, quum tabulas non recitat; reliquum est, ut stipulatum se esse dicat; praeterea enim quemadmodum certam pecuniam petere possit, non reperio.

Hier ist der Punkt, wo die bisherigen Interpreten ${ }^{37}$ ) einen wichtigen Umstand übersehen haben. Ich habe oben zwei Stellen der Rede angeführt, an welchen Cicero die Klage beschreibt; an beiden sagt er nicht kurzweg, dass pecunia certa eingeklagt sei, sondern er fügt noch hinzu, dass die Parteien eine Wette auf den dritten Theil eingegangen sind:

$\S 10$ pecunia tibi debebatur certa, quae nunc petitur per iudicem, in qua legitimae partis sponsio facta est...

\$ 14 pecunia petita est certa, cum tertia parte sponsio facta est ... (vgl. auch die vorhergehenden Worte: formulae et sponsioni ...)

Nun wissen wir aus Gaius 4, 13.171, dass die sponsio tertiae partis bloss bei certa pecunia credita stattfand. Dadurch bekommt die abstracte cond. certi doch wieder ein individuelles Gepräge, - ein Punkt, der mich noch später be-

37) Auch die Schriftsteller, welche gelegentlich auf den Process eingehen, vgl. als letzten Pernice, Labeo 1, 418. 
schäftigen wird. Was aber ist pecunia credita? Gaius 3, 124 definirt sie:

pecuniam creditam dicimus non solum eam, quam credendi causa damus sed omnem, quam tum, quum contrahitur obligatio, certum est debitum iri, id est quae sine ulla condicione deducitur in obligationem .... ${ }^{38}$ )

so dass also auch der Kaufpreis einer Sache darunter fiele. Aber sicherlich ist dies nicht der Ciceronianische Begriff von pecunia credita. Man erinnere sich an die bekannte Stelle von African, ${ }^{39}$ ) worin er erklärt, dass pecunia credita aus einer nuda pactio nicht entstehen könne, und dass der Procurator des Gläubigers, welcher die Schuld vom Schuldner eingezogen hat, nicht durch einen blossen Brief das Eingezogene in pecunia credita umwandeln könne. Danach ist auch der Kaufpreis, der vom Verkäufer dem Käufer creditirt wird, keine pecunia credita im Sinne Africans und ebensowenig in dem der Jurisprudenz zu Ciceros Zeit. Unzweifelhaft unterlag der Begriff der pecunia credita einer geschichtlichen Entwickelung; er begann mit dem Darlehn, ${ }^{40}$ ) er schritt fort zur Stipulation und dem Literalcontract, er erreichte seine Vollendung in der Zulassung einer formlosen Creditabrede über irgend eine Schuld. Auf der zweiten Stufe steht der Begriff noch in dem $\Lambda$ nfang des zweiten Jahrhunderts $n$. Chr.; wie man diese zweite Stufe erklären soll: ob mit Savigny, dass in der Stipulation und im Literalcontract ein fingirtes Darlehn gesehen wurde, oder mit Heimbach, dass alle Schulden aus negotia stricti iuris unter die pecunia credita subsumirt wurden: das kann hier völlig hingestellt bleiben. Für das Verständniss der Ciceronianischen Rede genügt die Feststellung, dass zu Ciceros Zeit der Begriff noch kein fertiger war; das Zeugniss des Africanus beweist dies unwiderleglich; ja, aus diesem Zeugniss folgt mit Nothwendigkeit, dass noch zu seiner Zeit

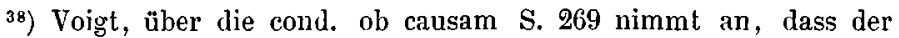
von Gaius anfgestellte Begriff der pecunia credita sich bloss auf die 1. Cornelia de satisdationibus bezog.

39) 1. 34 pr. D. mand. 17, 1. Bekanntlich ist Ulpian in 1. 15 D. de reb. cred. 12, 1 anderer Ansicht.

40) Voigt, über die cond. ob causam, $\$ 39$ sqq. nimmt die Stipulation als Ausgangspunkt an. 
zur pecunia credita bloss die adnumerata, stipulata, expensilata gerechnet wurden; ich wüsste wenigstens, wenn man mit Africanus die nuda pactio als Grund streicht, keinen Fall ausser jenen dreien anzuführen.

Nunmehr stellt sich die Klage des Fannius folgendermassen:

Er hat mit der cond. certae pecuniae geklagt, und ist deshalb befugt, irgend welche Causa zur Begründung der Klage auszuführen; im Nachstehenden wird gezeigt werden, dass er zwei Causae behauptet: Literalcontract und Societät. Er hat aber gleichzeitig die sponsio und restipulatio tertiae partis mit Roscius abgeschlossen, und diese Wette gewinnt er nur dann, wenn er die pecunia credita beweist (im vorliegenden Fall den Literalcontract); gelingt ilm dieser Beweis nicht, so gewinnt er zwar, wenn er eine andere Causa (im vorliegenden Fall die Societätsforderung) beweist, das eingeklagte Processobject von 50000 Sesterzen, er wird aber wegen der Restipulatio zu einem Drittel des Processobjects verurtheilt. Nach dieser Erörterung wird man die Worte Ciceros in $\S \S 14.15$ verstehen; nachlem er nämlich in den ersten 13 Paragraphen der Rede zu zeigen gesucht, dass keine pecunia credita vorliege, und den betreffenden Theil der klägerischen Ausführung sattsam widerlegt $z u$ haben sich berühmt, fährt er also fort: Hic ego si finem faciam dicendi, satis fidei et diligentiae meae, satis causae et controversiae, satis formulae et sponsioni, satis etiam iudici fecisse videar; cur secundum Roscium iudicari debeat... quid ergo est? Quod et reus is est, cui res et pecunia levissima et existimatio sanctissima fuit semper, et iudex est is, quem nos non minus bene de nobis existimare quam secundum nos iudicare velimus, et advocatio ea est, quam propter eximium splendorem ut iudicem unum vereri debeamus: perinde ac si in hanc formulam omnia iudicia legitima, omnia arbitria honoraria, omnia officia domestica conclusa et comprehensa sint, perinde dicemus. Illa superior fuit oratio necessaria, haec erit voluntaria; illa ad iudicem, haec ad C. Pisonem; illa pro reo, haec pro Roscio; illa victoriae, haec bonae existimationis causa comparata. 
Cicero thut einen Augenblick so, als habe Fannius durch Abschluss der sponsio tertiae partis den abstracten Charakter der cond. certae pecuniae abgestreift, als habe er sie dadurch in eine Klage mit den drei Causae der pecunia credita ungewandelt, und erklärt sein Amt deshalb als beendigt. Da er sich aber erinnert, dass diese Auffassung der sponsio tertiae partis weder der Gegner gelten lassen noch der Richter anerkennen wird, so erklärt er, freiwillig diejenigen Ausführungen geben $\mathrm{zu}$ wollen, wie sie die Natur einer abstracten Klage verlangt; das ist der Sinn der oben gesperrt gedruckten Worte, in denen er verspricht, die Formel so aufzufassen, als wären in ihr alle iudicia legitima, alle arbitria honoraria beschlossen; rednerisch fügt er noch die officia domestica hinzu, die doch überhaupt in keine Formel passen. Puchta ${ }^{41}$ ) hat diese Worte missverstanden; er führt die regelmässige Gliederung der Reden bei den Römern an: principium, narratio, divisio, confirmatio, confutatio, conclusio, und bemerkt, dass diese Theile in der Praxis nach Bedürfniss des Falles eine andere Ordnung erhalten konnten; dies konnte namentlich die narratio betreffen, und so habe denn Cicero die Narratio erst in dem zweiten Theil der Rede gebracht, der erste Theil (meint Puchta) sei bloss die Darlegung, dass der Anspruch des Fannius so, wie er erhoben worden, unbegründet sei. Meines Erachtens erhält der erste Theil der Rede gerade so gut eine Narratio wie der zweite; lie Narratio des ersten bezieht sich auf die klägerische Behauptung, dass pecunia credita vorliege, die des zweiten auf die Begründung des klägerischen Anspruchs aus der Societät.

\section{III.}

Pecunia credita ist $\mathrm{zu}$ Ciceros Zeiten, wie ausgeführt, dreifach : eine Schuld aus Darlehn, aus Stipulation, aus Literalcontract. Man streitet, welche Causa Fannius behauptet habe. Dass er kein Darlehn behauptet habe, sagt Cicero wiederholentlich; Heimbach und Puchta denken nun an Stipulation, ${ }^{42}$ ) bei Abschluss des Vergleichs in Vorprocess habe Roscius

41) Rhein. Mus. f. Jurispr. 5, $319 \mathrm{f}$.

${ }^{42}$ ) Auch Keller, Inst. S. 109 spricht gelegentlich diese Meinung aus. 
ebenso 100000 Sesterzen dem Flavius durch Stipulation versprochen, wie er ungekehrt von ihm durch Restipulation das Gegenversprechen empfing, dass er ihm die Hälfte des etwa von Flavius später Erhaltenen herauszahlen werde; Unterholzner, Schmidt und Bethmann-Hollweg denken an Literalcontract. Mit Sicherheit trete ich den letzteren bei. Cicero äussert sich so:

$\S 13$ : Jam duae partes causae sunt confectae; adnumerasse sese negat, expensum tulisse non dicit, quum tabulas non recitat; reliquum est, ut stipulatum se esse dicat; praeterea enim, quemadmodum certam pecuniam petere possit, non reperio. Stipulatus es? ubi? quo die? quo tempore? quo praesente? quis spopondisse me dicit? Nemo ...

$\$ 14$ Pecunia petita est certa, cum tertia parte sponsio facta est. Haec pecunia necesse est aut data ait expensa lata aut stipulata sit. Datam non esse Fannius confitetur; expensam latam non esse, codices Fannii confirmant; stipulatam non esse, taciturnitas testium concedit.

In sehr scharfen Nüancen zeichnen diese Worte die Stellung des Klägers zu den einzelnen Causae. Das Darlehn hatte Fannius aus drücklich in Abrede gestellt; den Literalcontract hatte er behauptet, aber nicht unter Berufung auf seinen codex accepti sondern (wic sich später ergeben wird) unter Berufung auf die Codices des Perperna und des Saturius sowie auf seine eigenen Adversarien; von der Stipulation hatte er völlig geschwiegen, sie weder vorgebracht noch darauf verzichtet; Cicero frägt deshalb (in $\S 13$ ), ob er sie noch vorbringen wolle, und constatirt (in $\S 14$ ), dass kein Zeuge daron rede; es kann kein Zweifel sein, dass Faunius darauf nicht recurriren wollte.

Was nun den Literalcontract betrifft, so würde ich es für einen Missbrauch erachten, wenn ich diese Materie einer neuen Prüfung unterzöge; noch unlängst (1873) gab Danz ${ }^{43}$ ) bloss einen Bericht über die bisher aufgestellten Meinungen, indem er hinzufügte, dass er nur Zweifels-, nicht aber Entscheidungsgriunde geben könne, dass er nichts positiv Besseres an Stelle des ihm zweifelhaft Erscheinenden zu setzen habe.

4:3) Lehrbuch der Gesch. des Ji. R. II, 49, 
Diese Worte möchte ich mir fast zu eigen machen. Ich kann aber umsomehr die soviel ventilirten Streitfragen bei Seite lassen, als sie grösstentheils in Theophilus' Paraphrase ihren Grund haben, welche den Literalcontract an selbständige Urkunden knüpft, während Gaius sie mit dem codex accepti et expensi in Verbindung bringt; die Rede Ciceros berührt nur den aus dem codex acc. et exp. hervorgehenden Literalcontract.

Thatsächlich muss Folgendes festgestellt werden:

1. Fannius hatte die eingeklagte Forderung nicht in seinen codex acc. et exp. eingetragen, sondern bloss in seine Adversarien. Es war dies ein unregelmässiges Verfahren, da der Sitte gemäss jeder, der einen Codex führte, die Eintragungen in denselben fast allmonatlich vornahm ( $\$ 8$ der Rede). Ob Fannius die Unterlassung rechtfertigte, ist nicht zu ersehen; Cicero wirft die rhetorische Frage auf, ob der Kläger zur Entschuldigung etwa anführen wolle, dass er die Schuld des Roscius nicht bekannt werden lassen wollte, ob er etwa von Roscius gebeten worden sei, die Eintragung zu unterlassen; er beantwortet sie sofort mit der Bemerkung, dass Fannius dann auch die Eintragung in die Adversarien hätte unterlassen müssen ( $\$ 9$ der Rede).

2. Dahingegen behauptete Fannius, dass seine Forderung in die Codices von M. Perperna und P. Saturius eingetragen worden sei. Dies ist der Sinn der Worte in $\S 3$ :

Paullo ante M. Perpernae, P. Saturii tabulas poscebamus, nunc tuas, C. Fanni Chaerea, solius flagitamus ....

Den Interpreten ist mit Ausnahme von Schmidt diese Stelle entgangen; Cicero hatte kurz vorher das Verlangen gestellt, Kläger solle sein en codex acc. et expensi vorlegen, und zugesagt, dass falls darin die Forderung eingetragen stände, er gegen die Verurtheilung des Verklagten nichts einwenden wolle. Hieran knüpft er die oben gedruckten Worte; er hatte also in dem uns verloren gegangenen Theil die Vorlegung der Codices von Perperna und Saturius verlangt, und das kann nur dann Sinn gehabt haben, wenn Kläger die Behauptung aufgestellt, dass die Forderung dort eingetragen sei. Cicero bezweifelt zwar das Vorhandensein der Eintragungen, und will deshalb die Codices einsehen; indess können wir nicht auf seine Seite treten; denn einerseits sitzt Perperna als 
Berather des Piso, Saturius als Sachwalter des Klägers im Gericht; andererseits hat sich Fannius nach den bisherigen Erörterungen durchaus nicht von irgend einer Seite her als unglaubwürdig erwiesen.

Nunmehr ergiebt sich die interessante Rechtsfrage: Ist unter so bewandten Umständen die Eintragung in die klägerischen Adversarien ein Ersatz für die mangelnde Eintragung in den klägerischen Codex? Bethmann-Hollweg und Schmidt formuliren die Frage ander's; sie meinen, es habe sich darum gehandelt, ob durch Eintragung in die Adversarien ein Literalcontract entstehe; Schmidt ${ }^{44}$ ) bejaht die Frage schlechthin, Bethmann-Hollweg lässt sie für Ciceros Ze it unentschieden, indem er hinzufügt, dass vielleicht damals die Bedingungen des Literalcontracts noch nicht ganz festgestanden haben. Diese schwankende Bemerkung ist sicherlich ungegründet; unzählige Stellen gerade bei Cicero zeigen, dass der Literalcontract damals ein völlig ausgebildetes Institut war. Auf der anderen Seite wäre es ein Räthsel, wie die Adversaria, wenn sie dem Codex acc. et exp. gleichgrestanden hätten, ihre juristische Bedeutung verlieren konnten. Wenn endlich dic alten Schriftsteller über den codex acc. et exp. sehr viel, über die Adversarien fast nichts berichten (- ausser in unserer Rede und einer Stelle bei Cornelius Nepos werden sie fast nirgends berüht -), so kann der Grund doch nur darin gelegen haben, dass die Adversarien juristisch keine Rolle spielten; auch die Justinianische Compilation enthält der Zeugnisse über den codex acc. et exp. mehrere; die Adversarien ubergeht sic mit Stillschweigen.

Ganz anders stellt sich die Sache, wenn für die klägerische Forderung zwei Eintragungen in Codices aufgewiesen wurden, freilich Eintragungen nicht in den klägerischen Codex, sonder'n wie bemerkt in die von Perperna und Saturius. Die klïgerische Behauptung lautete also folgendermassen: es sci ein wahres

44) Bei Bethmann-Hollweg finde ich seine Meinung nicht auffallend; er hat die Worte des $\$ 3$ überselıen; dahingegen habe ich es nicht rerstanden, wie Schmidt, trotzdem er den $\$ 3$ richtig interpretirte, dennoch bei der Fragestellung ihn ganz ausser Acht lassen komute; er ist dann zu dem Schluss gekommen, dass zu Ciceros Zeit die Eintragung in die Adversarien einen Literalcontract erzeugt. 
nomentranscripticium vorhanden, entstanden durch Eintragung in Codices; allerdings befinde sich dabei eine gewisse Anomalie, es fehle die Eintragung in den Codex des Klägers, diese werde aber durch die in die klägerischen Adversarien ersetzt.

Die Eintragung der nomina transcripticia in fremde Codices finden wir mehrfach erwähnt:

$\S 1$ der Rede: solent fere dicere, qui per tabulas hominis (hones)ti pecuniam expensam tulerunt: egone talem virum corrumpere potui, ut mea causa falsum in codicem referret... Cic. ad Att. 4, 18: haec pactio non verbis sed nominibus et perscriptionibus multorum tabulis quum facta esse diceretur...

Seneca de benef. II, 15: Utinam quidem persuadere possemus ut pecunias creditas tantum a volentibus acciperent! utinam nulla stipulatio emtorem venditori obligaret! nec pacta conventaque impressis signis custodirentur! fides potius illa servaret et aequum volens animus! Sed necessaria optimis practulerunt et cogere fidem quam spectare malunt: adhibentur ab utraque parte testes; ille per tabulas plurium nomina interpositis parariis facit...

Id em de benef. II, 23: Quidam norunt nomina secum fierinec interponi pararios nec signatores advocari nec chirographum dare; idem faciunt, qui dant operam, ut beneficium in ipso collatum quam ignotisimum sit ...

Gewöhnlich führt man noch eine Stelle aus der Justinianischen Compilation an:

l. 5 \& 8 D. comm. 13, 6: Si tibi codicem commodavero, et in eo chirographum debitorem tuum cavere feceris egoque hoc interlevero, si quidem ad hoc tibi commodavero, ut caveretur tibi in eo, teneri me tibi contrario iudicio....

Indess ist hier die Mitwirkung des Dritten lediglich auf die Hergabe des Codex beschränkt; auch ist nicht der Gläubiger der Eintragende, sondern der Schuldner stellt ein Chirographum aus. Die Stelle ist daher kein Beleg für das nomen facere per tabulas aliorum.

Welch eine Bedeutung hat die Eintragung in fremde Codices? Cicero erklärt, es sei des Beweises wegen, denn es 
sei eine Anmassung, wenn ein Kläger sich auf seinen Codex berufe ( $\$ 5$ der Rede); auch Seneca ist dieser Meinung, denn er vergleicht in der oben abgedruckten Stelle (de benef. II, 23) diejenigen, welche keine Nomina machen und keine pararii (dies sind eben die Dritten, deren Codices benutzt wurden) zuziehen lassen wollen, mit Leuten, welche empfangene Wohlthaten möglichst verbergen möchten. Hält man diesen Stellen Gaius 3, 131 und Gellius XIV. $2 \S 4$ entgegen, so möchte man auf den ersten Blick einen Widerspruch mit Cicero und Seneca annehmen. Gaius sagt nämlich bezüglich der nomina arcaria, dass der Codex obligationis factae testimonium praebere; dass er an den eigenen Codex des Darlehngebers denkt, ergiebt sich mit Nothwendigkeit daraus, dass er diesen als Eintragenden bezeichnet. ${ }^{45}$ ) Wenn nun der Codex die nomina arcaria beweist, so hat er unzweifelhaft bezüglich der nomina transscripticia die gleiche Kraft gehabt. Auch Gellius erzählt von einem vor ihm als Geschworenem verhandelten Darlehn:

sed qui petebat, neque tabulis neque testibus id factum docebat...

Da er fremde und eigene tabulae nicht scheidet, so legt er offenbar beiden Beweiskraft bei. Ich sehe aber keinen Widerspruch zwischen diesen beiden Schriftstellern einerseits und Cicero resp. Seneca andererseits; denn beide leugnen ja nicht die Beweiskraft des eignen Co(lex ${ }^{46}$ ); Cicero namentlich erklärt es für unanständig, davon Gebrauch zu machen: suum codicem testis loco recitare, arrogantia est $(\S 5$ der Rede);

aber gerade diese Bezeichnung zwingt zu dem Schluss, dass juristisch der eigne Codex Beweiskraft liefert; und dies wird bestätigt durch die Worte des $\S 7$ :

Itaque adversaria in iudicium protulit nemo, codicem protulit, tabulas recitavit...

Die Eintragung in fremde Codices unterstiitzte den Beweis,

45) Wenn das nomen in fremde Codices eingetragen wurde, so war der Eigenthümer des Codex der Eintragende; dies ist schon an sich selbstverständlich und ergiebt sich aus $\$ 1$ unserer Rede; derselbe ist auf der vorhergehenden Seite abgedruckt.

46) Anders Heimbach (Creditum S. 609); er legt deshalb der Stelle von Gaius einen höchst gekünstelten Sinn unter, nämlich dass der eigene 
erhob ihn über jeden Zweifel, namentlich in Fällen, wenn der Beklagte seinen Codex, in welchem das Nomen nicht eingetragen war, zum Zwecke des Gegenbeweises producirte.

Ist der fremde Codex nur ein Beweismittel, so begreift man, dass Gaius 3, 128 sqq. vollständig von der Eintragung in denselben schweigt. Gaius erörtert die Entstehungsgründe der Obligationen; es entsteht aber die Literalobligation durch Eintragung in den eignen Codex.

Damit ist aber auch die ganze Werthlosigkeit der klägerischen Behauptung aufgezeigt. Die Eintragung in den eignen Codex hat eine ganz andere Bedeutung als die in dẹn fremden, die erstere kann deshalb durch die letztere nicht ersetzt werden, und die letztere ist nicht im Stande, das, was der Eintragung in die eignen Adversaria fehlt, zu ergänzen.

Man erwartet nun, dass Cicero Folgendes ausführen würde. Es handle sich um einen Formalcontract, der, wenn auch nur im Geringsțen in der Form gefehlt worden sei, nicht zur Giltigkeit gelange; im vorliegenden Falle könne man darüber streiten, ob die Form völlig mangle oder ob sie mangelhaft sei; erforderlich sei die Eintragung in den eignen Codex; statt dessen behaupte Kläger die Eintragung in fremde Codices und die in die eignen Adversaria; er zerlege das Eine und untheilbare Erforderniss in zwei incommensurable und unter einander nicht addirbare Halbheiten; das sei überall unzulässig, geradezu unerträglich sei es bei einem Formalcontract.

Man erwartet (sagte ich) eine solche Ausführung; aber Cicero giebt scheinbar eine andere; er schildert die nachlässige Abfassung der Adversaria, und die besonders aufmerksame des Codex; die Adversarien nennt er perscriptiones et liturae, d. h. bei ihnen kommen Durchstreichungen vor, das Eingetragene kann also nicht den Anspruch auf Richtigkeit erheben; er nennt sie deiecta, weil sie nach Kurzem vernichtet werden ( $\$ \S 6$ und 7 der Rede). Ich leugne nicht, dass auf den ersten Anblick die Ausführung Ciceros den Eindruck macht, als wolle er darthun, dass die Adversarien unmöglich als Beweis mittel angezogen werden dürfen, während

Codex nur unter der Bedingung die nomina arcaria beweise, wenn zugleich eine Eintragung in fremde Codices erfolgt ist. 
der Codex ein untrügliches Beweismittel ist. Allein Cicero macht doch auch eine Aeusserung, welche von einem ganz anderen Gesichtspunkt ausgeht. Quodsi (beginnt er den $\S 6$ ) eamdem vim, diligentiam auctoritatemque habent adversaria quam tabulae, quid attinet, codicem instituere, conscribere. ordinem conservare, memoriae tradere literarum vetustatem? Cicero spricht also den Adversaria nicht bloss die Beweisskraft sondern die vis, diligentia, auctoritas des Codex ab; das ist der von mir oben entwickelte Gesichtspunkt; er führtaus, dass der Codex unmöglich durch die Adversarien vertreten werden könne. Man ist versucht, dem Cicero einen Vorwurf daraus zu machen, dass er diesen Gesiclitspunkt nicht selbständig darlegt, dass er ihn mit der Beweisfrage vermischt hat; allein liess sich denn beides absolut von einander getrennt halten? Ist nicht die Nachlässigkeit resp. die Sorgsamkeit der Abfassung einerseits der Grund dafiir, dass dem einen die Beweiskraft abgesprochen wird, während sie dem anderen zukommt, andererseits dafür, dass der Literalcontract aus dem einen nicht hervorgehen kann, während er mit dem anderen verknüpft ist? Ich schlage dieses Argument so hoch an, dass ich nicht glaube, darauf Gewicht legen zu müssen, dass Cicero nur ein halber Jurist war, und dass die Rede vor Nichtjuristen gehalten wird, dass mithin Verschiebung oder Verwechselung der Gesichtspunktc leicht erklärlich ist. Nicht Cicero trifft ein Vorwurf sondern - wenn man will - Roscius; dieser hatte sich dem Vergleichsvorschlag des Piso gefügt, er zahlte die Hälfte der Vergleichssumme mit 50000 Sesterzen, er nahm die Restipulation des Fannius entgegen, sicherlich erfolgte die Eintragung der Vergleichsschuld in die Codices des Perpenna und Saturius mit seiner (des Roscius) Einwilligung ${ }^{47}$ ); aber Fannius unterliess - aus welchem

47) Dass die Einwilligung des Schuldners nötliig war, ergieltt sich aus $\$$ L unserer Rede (scripsisset ille, si non iussu huius expensum tulisset?) und aus Valerius Maximus facta et dicta VIII. $2 \S 2$ (1. Visellius Varro ab Otalicia Lateranensi expensa ferri sibi passus est eo consilio, ut, si decessisset, ab heredibus eius summam peteret, libidinosam liberalitatem debiti nomine colorando). Die weitergehende Behauptung Heimbachs (Greditum S. 325 ff.), dass der Schuldner nicht bloss consentirend sondern schreibend mitgewirkt habe, stützt sich einerseits auf 
Grunde, ist nicht zu ersehen - die Eintragung in den eigenen Codex, und von diesem sei es zufälligen, sei es durch Absicht oder Nachlässigkeit veranlassten Umstand machte Roscius Gebrauch, um der Klage zu entgehen. Aber Roscius erklärte dieses Vorgehen durch eine Behauptung, die, wenn wahr, ihn vor jedem moralischen Tadel sicher stellt, durch die Behauptung nämlich, dass Flavius später an Fannius 100000 Sesterzen gezahlt habe; zwar konnte diese. Behauptung nach den damaligen Grundsätzen über Compensation in dem gegenwärtigen Process nicht vorgeschützt werden; auch stand der Beweis dafür juristisch auf schwachen Füssen (S. 129), jedenfalls aber war er soweit erbracht, dass, falls der Einwand zulässig gewesen wäre, dem Beklagten - modern gesprochen - ein Reinigungseid hätte auferlegt werden müssen; bei solcher Sachlage erscheint mir Roscius wohlbefugt, einen anderweiten Mangel der Klage (die Nichteintragung in den Codex des Fannius) geltend zu machen, und ich möchte ihm deshalb auch nicht einen moralischen Vorwurf machen.

Das Resultat der bisherigen Erörterung ist, dass die Klage des Fannius, soweit sie pecunia credita behauptet, abgewiesen werden musste.

IV.

Der zweite Theil der Rede beginnt mit dem $\S 16$. Dass es sich hier um die Begründung der klägerischen Forderung aus der Societät handelt, und dass die Behauptung von Bethmann-Hollweg, es handle sich um causa furtiva oder um Be-

die Paraphrase des Theophilus III, 21, andererseits auf J. 13 D. ad sct. Vell. 16, 1. Allein die Stelle bei Theophilus bezieht sich (- ganz abgesehen davon, ob dem Theophilus Glaubwürdigkeit zukommt -) jedenfalls auf einen Literalcontract, welcher durch selbständige Urkunden und nicht durch Eintragung in den codex acc. et exp. perficirt wurde, und die 1.16 cit. beruht darauf, dass $\mathrm{n}$ ach vollzogener Eintragung in den Codex des Gläubigers der Schuldner gleichfalls in seinen Codex eine Eintragung machte $(\S 2$ unserer Rede: non scripsisset hic, quod sibi expensum ferri iussisset? nam quemadmodum turpe est scribere, quod non debeatur, sic improbum est non referre quod debeas); aber der Literalcontract entstand, wie aus Gaius mit Sicherheit hervorgeht, durch die Eintragung des Gläubigers. 
reicherung ${ }^{48}$ ), auch nicht den Schatten eines Beweises für sich hat: kann aufs klarste dargethan werden.

Sofort im $\$ 16$ frägt Cicero den Fannius, worauf er seine Forderung stiitze, ob auf Societät oder auf Liberalität des Roscius? Mit der cond. certi konnte cibensosehr die eine wie die andere geltend gemacht werden. Die Antwort erfolgt in Form einer rhetorischen Frage dahin, dass es Societät sei. Daran schliesst sich bis $\$ 24$ inclusive eine breitgetretene Darstellung des Charakters des Roscius und der Gesinnung des Fannius. Erst im $\S 25$ nimmt Cicero die Erörterung der der Sache selbst wieder auf, und wiederum frägt er den Kläger, warum er nicht die actio pro socio (sondern die condictio certi) angestellt habe; die Antwort lautet, dass Kläger im Hinblick auf die alte Bekanntschaft nicht iudicio gravi klagen wollte:

$\S 25$. Quae quum ita sint, cur non arbitrum pro socio adegeris Q. Roscium quaero. Formulam non noras? Notissima erat. Iudicio gravi experiri nolebas? Quid ita? Propter familiaritatem veterem....

Diese Worte lassen den Kläger Fannius in gutem Licht erscheinen; die Verurtheilung des Beklagten in der act. pro socio hatte bekanntlich dessen Infamie zur Folge; es ist aber gute Römische Sitte, dass der Gläubiger seinen Schuldner vor dem Verlust der Ehre möglichst zu bewahren suchte; Cicero berichtet hiervon in einer anderen Rede ${ }^{49}$ ); nur gezwungen und widerwillig greift der Gläubiger zu diesem Mittel; vorher versucht er jedes andere, demn Niemand will dem Anderen den Strick um den Hals werfen, jeder will lieber als schonend gelten denn als rachsüchtig.

Nun ist eben die condictio certi das Mittel, das von dem Socius selbst im Fall der Verurtheilung die Infamie fern hält; denn als Klage ohne Causa, als abstracte Klage giebt sie nicht die Möglichkeit, dem Beklagten den Vorwurf zu machen, dass er die Societätspflichten verletzt habe; farblos ist die Klage, farblos muss auch das Urtheil sein; wie die erstere, so wird auch das letztere nicht an eine bestimmte Causa an-

${ }^{48)}$ A. a. O. Seite 819.820 .

49) Pro Quinctio cap. 16 sqq. 
geknüpft. Es ist dies noch in der Justinianischen Compilation ausgesprochen:

1. $35 \mathrm{D}$. de obl. et act. 44, 7: Cessat ignominia in condictionibus, quamvis ex famosis causis pendeant.

Meine obige Ausfïhrung giebt die Begründung der Stelle, sie giebt auch die Erklärung des Verfahrens von Fannius; ihm bot die cond. certi insofern einen Vortheil, als er in ihr zwei Causae verbinden konnte (Literalcontract und Societät), aber sie bot auch dem Roscius den Vortheil, sich sicher zu wissen gegen die mit einer etwaigen Verurtheilung verbundene Infamie. Im Besitz dieses Vortheils und im Bewusstsein seiner Unentreissbarkeit hat Cicero leichtes Ablehnen; er behauptet, Kläger hätte entweder das arbitrium pro socio anstellen oder die Klage unangestellt lassen müssen ( $\$ 25$ der Rede). Aber er fügt sich der vom Kläger herbeigeführten Processgestaltung und geht nunmehr za einer genaueren Darlegung der die Societät betreffenden Thatsachen über.

Bevor ich diese beurtheile, will ich nur noch den Klagantrag erläutern. Aus der Societät klagend konnte Fannius nur das halbe Grundstück verlangen; um die cond. certi zu begründen, musste er dasselbe schätzen, und da er es auf 100000 Sesterzen schätzte ( $\$ 32$ der Rede), so konnte er das Petitum auf 50000 Sesterzen bestimmen. Man hat das Schätzungsrecht des Klägers als etwas Postjustinianisches, Byzantinisches hinstellen wollen ${ }^{50}$ ) ( - in den Basiliken ist es zweifellos anerkannt ${ }^{51}$ ) -), unsere Rede weist seine Existenz schon in republikanischer Zeit nach. -

Nunmehr wende ich mich zur Betrachtung der Societät.

Zuerst muss die Frage aufgeworfen werden: besteht wirklich eine Societät zwischen Fannius und Roscius? bestand sie namentlich zu der Zeit, wo Roscius sich mit Flavius verglich? Die Frage ist von den Interpreten bisher übersehen worden, sie setzten den Bestand der Societät als etwas Selbstverständliches voraus.

so) Voigt, cond. ob causam S. 818f. Heimbach, Creditum S. 116.576f.

51) Vgl, z. B. die Scholien von Stephanus ex causa legati, et damni et furti, et fideicommissi universalis in Heimbachs Basilikenausgabe II, $596 \mathrm{f}$. 
Und doch brauche ich nicht erst weitläufig zu beweisen, dass die Societät bezüglich des Panurgus durch dessen Tödtung aufgehoben worden war. Die Tödtung erzengte für jeden Miteigenthümer eine besondere actio legis Aquiliae; zwischen den Klagen der beiden (bisherigen) Socii bestand nicht der geringste Zusammenhang; jeder konnte sie selbständig geltend machen ${ }^{52}$ ). Sicherlich gehen hierauf die Worte Ciceros im $\xi 38$ :

Cur in re tam vetere, in negotio iam confecto, in societate dissoluta nova haec restipulatio interponitur?

Die Frage ist also, ob nach der Tödtung (genauer: zwischen der Tödtung und dem von Roscius mit Flavius eingegangenen Vergleich) eine neue Societät abgeschlossen worden ist? Die hierher bezüglichen Thatsachen, welche einer Prüfung unterzogen werden müssen, sind: Roscius macht den Fannius zu seinem Cognitor in dem gegen Flavius anzustellenden Process, und Fannius stellt den Process theils für sich, theils als Cognitor des Roscius an. Liegt hierin eine Societät?

An und für sith gewiss nicht; die Bestellung eines Cognitor ist ein mandatum agendi; ein solches kann ebensosehr einem völlig Uninteressirten wie einem Gleichinteressirten ertheilt werden; ein mandatum agendi an einen Gleichinteressirten bleibt Mandat, und begründet nicht eine Societät. Die Processführung durch den zum Cognitor bestellten Gleichinteressirten mag thatsächlich eine für Beide gemeinsame sein, juristisch ist sie ein Neben einander $\mathrm{z}$ weier Processführungen.

Aber wie nahe liegt diesem Mandat an den Gleichinteressirten die Societät! Die Grenze ist ungemein schmal, und mit zwei Worten wird sie überschritten. Man braucht bloss die Worte hinzuzufügen, dass die Erfolge des geführten Processes die beiden Gleichinteressirten gleich berühren sollen; dann ist die Societät fertig. Die Societät macht die beiden eingeklagten Forderungen nicht zu gemeinsamen; jeder bleibt Gläubiger in seiner bisherigen Forderung, er behält also auch das Dispositionsrecht über dieselbe, aber wenn er disponirt,

52) Und dennoch sagt Puchta a, a. O. S. 324: ,die beiden Socii hatten gemeinschaftlich, jeder für seinen Antheil am getödteten Sclaven, die act. leg. Aquiliae gegen Flavius". 
so muss er dem Gesellschafter gegenüber culpa in concreto prästiren, und was er durch die Disposition erworben, muss er mit dem Gesellschafter theilen. Es ist die Sachlage dieselbe wie im ersten Falle der

1. 58 pr. D. pro soc. $17,2: \ldots$ Quum tres equos haberes et ego unum, societatem coivimus, ut accepto equo meo quadrigam venderes et ex pretio quartam mihi redderes. $\mathrm{Si}$ igitur ante venditionem equus meus mortuus sit, non putare se Celsus ait, societatem manere, nec ex pretio equorum tuorum partem deberi; non enim habendae quadrigae sed vendendae coitam societatem. Ceterum si id actum dicatur, ut quadriga fieret eaque communicaretur, tuque in ea tres partes haberes, ego quartam, non dubie adhuc socii sumus.

Hier wird eine societas vendendae quadrigae von derjenigen habendae quadrigae unterschieden; bei Obligationen ist die societas habendorum nominum undenkbar, weil nach dem Satz der zwölf Tafeln nomina ipso iure divisa sunt; analog der societas vendendae quadrigae ist "nur eine societas exigendorum nominum möglich, und hier wie dort muss, was der venditor resp. der exactor einnimmt, mit dem Gesellschafter getheilt werden.

Wenden wir uns zur Rede Ciceros.

Sicherlich behauptete Kläger eine societas exigendorum nominum; er ging sogar soweit zu behaupten, dass Roscius den Vergleich nicht bloss über seine sondern (offenbar als negotiorum gestor des Fannius) zugleich über dessen Forderung an Flavius abgeschlossen habe:

$\S \S 34.35$. De tota re, inquit, decidisti ...; societatis non suas lites redemit, quum fundum a Flavio accepit...

Diese Behauptung des Klägers war leicht zu widerlegen; Flavius hatte sich ja von Roscius nicht die cautio rati (amplius a se neminem petiturum in $\$ \S 35$. 36 genannt) bestellen lassen; Fannius hatte ja in der oben viel behandelten Restipulation dem Roscius die Hälfte von dem versprochen, was er von Flavius noch eintreiben werde; kurz, auch nach dem Vergleich zwischen Roscius und Flavius behielt Fannius seine Forderung an den letzteren ( $\$ 34-39$ der Rede). 
An der Behauptung der societas exigendorum nominum hielt Kläger auch fest, falls der Vergleich $z$ wischen Roscius mit Flavius sich bloss auf seine Forderung bezog, und er forderte auch in diesen Falle die Herausgabe des halben Werththeiles mit 50000 Sesterzen :

$\S 52$. Petisse, inquit, suam partem Roscium a Flavio confiteor, vacuam et integram reliquisse Fannii concedo, sed quod sibi exegit, id commune societatis factum esse contendo...

So hängt denn die Entscheidung des Processes einzig und allein von der Frage ab: bestand $z$ wischen Roscius und Fannius ein blosses Processmandat oder zugleich eine societas exigendorum nominum?

Wie stellt sich Cicero zu dieser Frage? Ich gebe zu, dass er die Societät nicht mit der wünschenswerthen Schärfe verneint; er nennt sogar Fannius und Roscius socii und spricht von deren partes - Ausdrücke, die bei Forderungen sicherlich unjuristisch sind, da nomina ipso iure divisa sunt. Scheinbar reitet Cicero auf dem Satz: was Jemand für sich erwirbt, braucht er einem Andern nicht herauszugeben. Nun ist doch aber dieser Sat $z$ so unwahr, dass man ihn einem Advocaten, der sicherlich durch Roscius' Vermittlung mit bedeutenden Juristen den gegenwärtigen Process durchgesprochen hatte, nicht zutrauen darf. Den wahren Sinn der Behauptung Ciceros erkennt man, wenn man einige andere Sätze hinzunimmt; er erinnert den Kläger daran, dass nur, weil er der Cognitor des Roscius war, er verpflichtet war, alles rom Flavius Erhaltene mit Roscius zu theilen, er zieht den Fall der Miterben heran, und zeigt, wie jeder Miterbe durch Verfügungen über seinen 'Theil für sich allein handelt. Das heisst doch mit anderen Worten: Derjenige, der in einer factischen oder in einer zufälligen Gemeinschaft mit einem Anderen steht, hat nicht die Pflichten eines Gesellschafters, er handelt für sich und lediglich für sich. Dazu tritt noch die Aeusserung in $\S 38$ : in societate dissoluta, die Cicero von der Zcit der Restipulation macht, also von der Zeit, wo die Pisonische Vergleichsproposition bereits ergangen, wo Fannius von Roscius längst zum Cognitor gemacht worden war. 
Mit anderen Worten: Cicero leugnet die societas exigendorum nominum; und nach dem vorliegenden Material hat er Recht. Trotzdem ich oben die Grenze zwischen mandatum exigendi an einen Gleichinteressirten und societas exigendorum nominum als sehr schmal und als leicht überschreitbar erklärte, so muss ich sie im vorliegenden Fall als gewahrt ansehen; nichts ist geschehen, als dass Roscius den Fannius zum Cognitor bestellte; wäre eine weitergehende Abrelle zwischen ihnen getroffen gewesen, so hätte sie Cicero in dem uns erhaltenen Theile der Rede erwähnen müssen; ein kluger Advocat übergeht nicht die bedeutendsten Stiitzpunkte seines Gegners, er stellt sie auch nicht zurück, sondern er greift den Stier bei den Hörnern und ringt mit ihm; auf mich macht der erhaltene Redetheil einen so geschlossenen, einheitlichen Eindruck, dass ich mir nicht denken kann, es sei in dem untergegangenen Theil auch nur irgend eine wesentliche Thatsache oder Rechtsfrage erörtert worden, welche unser aus dem erhaltenen Theil geschöpftes Urtheil modificiren könnte. Puchta ${ }^{53}$ ) und Bethmann-Hollweg ${ }^{54}$ ) nehmen eine Societät an; sie bewegen sich, wie mir scheint, in dem Irrthum, als ob durch die Tödtung des Panurgus die Societät nicht aufgelöst wäre, und als ob der von Roscius mit Flavius abgeschlossene Vergleich noch unter dem Gesetze dieser angeblich noch fortdauernden Societät gestanden hätte. Nichtsdestoweniger gelangt Bethmann-Hollweg zur Freisprechung des Roscius deshalb, weil er annimmt, dass Roscius die Hälfte der 100000 Sesterzen, die Flavius an Fannius gezahlt habe, compensiren dürfe; die Compensation sei zulässig, weil es sich um Feststellung der Bereicherung des Roscius handle, weil die Klage eine Bereicherungsklage sei. Ich habe schon oben (S. 129) gezeigt, auf wie schwachen Füssen der Beweis der Zahlung von Flavius an Fannius stand, und ich kann nicht zugeben, dass auf diesen ungenügenden Beweis hin die Freisprechung des Roscius erfolgen durfte.

Ich gelange zur Freisprechung des Roscius auf Grund der Feststellung, dass nach dem Tode des Panurgus die Societät aufgelösst wurde, ohne Ansprüche unter den bisherigen

53) A. a. O. S. $324 \mathrm{f}$.

54) A. a. O. S. 825 . 
Socien zu hinterlassen, und dass später keine neue Societät unter ihnen eingegangen wurde. Vielleicht wirl behauptet werden, dass die Freispreclung auch bei Annabme einer societas exigendorum nominum erfolgen musste, da ja Roscius die Hälfte der Pisonischen Vergleichsproposition an Fannius bezahlt hatte; allein nach der ausdrücklichen Mittheilung von Cicero sollte Roscius die ganzen 100000 Sesterzen pro opera, pro labore, quod cognitor fuisset, quod vadimonia obisset ( $\$ 38$ (ler Rede) zahlen ${ }^{55}$ ); die (angebliche) Societätsschuld blieb also von der Zahlung unberiilnt. - - -

Ich schliesse mit der Andeutung eines umfassenderen Gesichtspunkts. Ist nämlich die obige Darstellıng gegründet, so ist die Condictio keine Klage aus Darlehn, Stipulation, Literalcontract, keine Klage aus der Bereicherung u. s. w.; sie gehört überhaupt nicht in das materielle Recht sondern in den Process; die Kellersche Behauptung, dass die condictio certi in späterer classischer Zeit auf jeden persönlichen Anspruch ausgedehnt worden sei, muss dahin umgewandelt werden, dass sie von Anfang au bei jedem persönlichen Anspruch zulässig war. Unsere bisherige Condictionenlehre muss alsdann eine völlige Umgestaltung erfahren. Die weitere Ausfiihrung dieses Gedankens hoffe ich anderweitig zu geben.

55) Vgl. oljen S. 128 Note 25.

\title{
Zur Lehre vom legatum optionis.
}

\author{
Von \\ Herrn Dr. K. Bernstein \\ in Berlin.
}

I.

Heut zu Tage versteht man unter dem legatum optionis nichts als einen einzelnen Fall des legatum generis, denjenigen, wo die Wahl ausdrücklich dem Legatar hinterlassen ist. Seit 